\title{
The Role of Trp-p8 Combined with PSADTZ Determinated in the Early Diagnosis of Prostate Cancer*
}

\author{
Xinsheng Zhang1\#, Ying Zhang' ${ }^{2}$ Panxing $\mathrm{Wu}^{1}$, Shuijiao Liu ${ }^{1}$, Jianyu Zhou ${ }^{3}$ \\ ${ }^{1}$ Department of Urology, Taizhou Central Hospital, Taizhou, China \\ ${ }^{2}$ Department of Blood Transfusion, Taizhou Central Hospital, Taizhou, China \\ ${ }^{3}$ Department of Ultrasound Imaging, Taizhou Central Hospital, Taizhou, China \\ Email: "zhangxs0624@163.com
}

Received 24 May 2016; accepted 13 June 2016; published 16 June 2016

Copyright (C) 2016 by authors and OALib.

This work is licensed under the Creative Commons Attribution International License (CC BY).

http://creativecommons.org/licenses/by/4.0/

(c) (i) Open Access

\begin{abstract}
Objective: To study the expression of Transient receptor potential p8 (Trp-p8) in prostate tissues of prostate-specific antigen (PSA) in "grey district" with different PSA density of transition zone (PSADTZ) interval and explore the role of Trp-p8 and PSADTZ determinated in the early diagnosis on prostate cancer. Methods: Immunohistochemical and RT-PCR were applied to determinate Trpp8 in the prostate cancer and benign prostatic hyperplasia group with different PSADTZ interval, which were both 30 specimens. The difference of expression level was judged and analyzed. Results: The expression of Trp-p8 was weak or negative in the benign prostatic hyperplasia group, while it appeared to be far more abundant in prostate cancer group and was higher in PSADTZ group, the difference was of statistical significance. Conclusions: The expression of Trp-p8 in prostate tissues of PSA in grey district was different. The expression in prostate cancer was higher than that in benign prostatic hyperplasia group.
\end{abstract}

\section{Keywords}

Trp-p8, Prostate Cancer, Benign Prostatic Hyperplasia, Immunohistochemical, PSADTZ, RT-PCR

Subject Areas: Oncology

\section{Introduction}

Prostate cancer (PCa) is now the fastest-rising incidence of tumors of the urinary tract diseases. The treatment is

\footnotetext{
*Project: Taizhou Science and Technology Plan Projects (131KY14-2).

${ }^{\#}$ Corresponding author.
}

How to cite this paper: Zhang, X.S., Zhang, Y., Wu, P.X., Liu, S.J. and Zhou, J.Y. (2016) The Role of Trp-p8 Combined with PSADTZ Determinated in the Early Diagnosis of Prostate Cancer. Open Access Library Journal, 3: e2626. 
effective if it has been early detected and timely diagnosed; otherwise it becomes costly and limited in advanced prostate cancer. In view of the fact that PSA is still limited in the early diagnosis of prostate cancer, currently study on the early diagnosis of prostate cancer is more. Transient receptor potential p8 (Trp-p8) is a member of the $\mathrm{Ca}^{2+}$ ion channel family. The polypeptide chain potential and transient receptor families of calcium channels are homologous name. Research on Trp-p8 and prostate cancer has not been reported in the last century. Recent studies [1] discover Trp-p8 of prostate cancer may be a cancer-causing gene, but the relationship between Trp-p8 and prostate cancer research is rarely reported at home and abroad. There are rare research reports about Trp-p8 expression in the "grey district" (PSA: 4 - $10 \mathrm{ng} / \mathrm{ml}$ ) in prostate tissue particularly.

PSADTZ is the ratio of serum PSA and transition zone volume of the prostate and is used as a marker for early diagnosis of prostate cancer. Prostate hyperplasia occurred mainly in the transitional zone, while PCa mainly occurred in the peripheral zone. Moon [2] found that the PSADTZ of PSA in grey district diagnosis of PCa efficiency was significantly higher than that of the FPSA/TPSA. Trp-p8 protein expression in the prostatic tissue of different PSADTZ interval was detected through immunohistochemistry. Trp-p8-mRNA was studied by RT-PCR in blood of patients to discuss significance of joint detection of PSADTZ and Trp-p8 in early diagnosis of prostate cancer. Our reports are as follows:

60 cases were collected for prostate biopsy in our hospital from 2012.6 to 2013.12 while PSA $>4 \mathrm{ng} / \mathrm{ml}$. Blood PSA and Trp-p8-mRNA expression levels were measured and prostate volume, transition zone volume were determinated by B ultrasound. PSADTZ was calculated and divided into the following 3 sections: PSADTZ $<0.35 \mathrm{ng} / \mathrm{ml}, 0.35 \mathrm{ng} / \mathrm{ml} \leq$ PSADTZ $<0.5 \mathrm{ng} / \mathrm{ml}$, PSADTZ $\geq 0.5 \mathrm{ng} / \mathrm{ml}$. We analyzed Trp-p8 combined with PSADTZ correlation measurement and prostate cancer according to the expression level of Trp-p8mRNA copy number and PSADTZ value classified and compared with pathological results.

\section{Methods}

\subsection{Immunohistochemistry}

Test reagent rabbit anti-human Trp-p8 is bought from Shanghai Culture Biotechnology limited company, SP immunohistochemical kits and reagents such as $3 \% \mathrm{H}_{2} \mathrm{O}_{2}$, PBS, DAB are bought from Beijing Zhongshan Biotech Company.

Preparation of tissue samples: Samples were wax embedded, $4^{\circ} \mathrm{C}$ saved and height $4 \mu \mathrm{m}$ made from paraffin after formalin fixation, dehydration, clearing and dipping.

H-E staining wax into the water, the transparent gradient alcohol dehydration, and rhamsan gum tablets.

SP immunohistochemical staining of tissue slices sliced wax into the water, washing $5 \min \times 3$ time, $3 \% \mathrm{H}_{2} \mathrm{O}_{2}$ incubate $15 \mathrm{~min}$, PBS $95^{\circ} \mathrm{C}-98^{\circ} \mathrm{C}$ citrate-buffer fix $15 \mathrm{~min}$ microwave oven, cooled to room temperature. Dry the slices around the water, normal serum incubation at room temperature in closed 15min, lens tissue wipe, incorporated a fluid-resistant, incubate at $37^{\circ} \mathrm{C} 2$ hours (0.01M PBS solution instead of a resistance as a negative control, the remaining steps do not change). PBS rinse $5 \mathrm{~min} \times 3$ time, adding secondary antibodies biotinylated, incubate at $37^{\circ} \mathrm{C} 15 \mathrm{~min}$. PBS rinse $5 \mathrm{~min} \times 3$ time, adds third antibodies, incubate at $37^{\circ} \mathrm{C} 15 \mathrm{~min}$, PBS rinse 5 min $\times 3$ time. DAB color at room temperature and microscopically controlled reaction time, full washing suspension reaction, hematoxylin counterstain. Dehydration transparent rubber seal section is judged by the same pathologist.

\subsection{RT-PCR}

Reagent TRIZOL kit, TIANScript RTKit (first strand cDNA synthesis Kit) (Tiangen biotech Co. Ltd.), TaqDNA polymerase (Promega)

Step RT-PCR Take $10 \mathrm{ml}$ blood samples, total RNA was extracted with TRIZOL kit, according to TIANScript RTKit (first strand cDNA synthesis Kit) manual synthesis of cDNA, initial total RNA samples were $1 \mu \mathrm{g}$. The following primers of the TRP-P8 was designed according to the literature [3]: the upstream primer: 5'-gCCCAgTgATgTggACAgTA-3', 5'downstream primer: -ATC TCC TCTgCgTTgTCgTT-3'. PCR reaction conditions were: $94^{\circ} \mathrm{C}$ pre degeneration in $2 \mathrm{~min}, 94^{\circ} \mathrm{C}$ degeneration in $30 \mathrm{~s}, 58^{\circ} \mathrm{C}$ for $45 \mathrm{~s}, 72^{\circ} \mathrm{C}$ for $90 \mathrm{~s}$, a total of 35 cycles and ended after $10 \mathrm{~min}$ at $72^{\circ} \mathrm{C}$. The products were electrophoresed in $20 \mathrm{~min}$ in $10 \%$ agarose gel containing nucleic acid and observed under UV transilluminator.

Determination of PSADTZ and Trp-p8 protein expression levels 60 cases of via rectum ultrasound in patients 
with three-dimensional determination of prostate size are determined by the same ultrasound practitioner. We calculate PSADTZ combined with prostate volume, transition zone volume and serum TPSA value. The results of immunohistochemical experimental were analyzed using graphic data imaging systems. The expression of Trp-p8 in high power count 100 cells or stromal cells based on the percentage of positive cells and staining intensity of specimen: negative (-): no staining cells; weakly positive ( \pm ): positive cells $<40 \%$, dye tints; positive $(+)$ : positive cells in the $40 \%-80 \%$ between the staining intensity; strongly positive (++): the number of positive cells $>80 \%$, dyed darker.

\subsection{Results and Statistics}

Statistical methods: The PSADTZ value is divided into the following 3 interval: PSADTZ $<0.35 \mathrm{ng} / \mathrm{ml}, 0.35$ $\mathrm{ng} / \mathrm{ml} \leq \mathrm{PSADTZ}<0.5 \mathrm{ng} / \mathrm{ml}$, PSADTZ $\geq 0.5 \mathrm{ng} / \mathrm{ml}$. We statistics individually the group number, intensity of expression of Trp-p8 proteins and blood sample Trp-p8-mRNA abundance of the benign prostatic hyperplasia and prostate cancer in each interval. We calculate of sensitivity and specificity for predicting prostate cancer. The relative content of Trp-p8-mRNA is instead of the ratio: target gene/(GAPDH absorbance $\times$ area). All data are counted with SPSS10.0 software package while among groups with two independent samples t-test. Measurement data to mean $\mathrm{t}$ standard deviation $(\mathrm{x} \pm \mathrm{s}$ ) that the groups were compared with two independent samples t-test and $P<0.05$ considered to have significant differences.

Results are shown in Tables 1-5 and Figures 1-4.

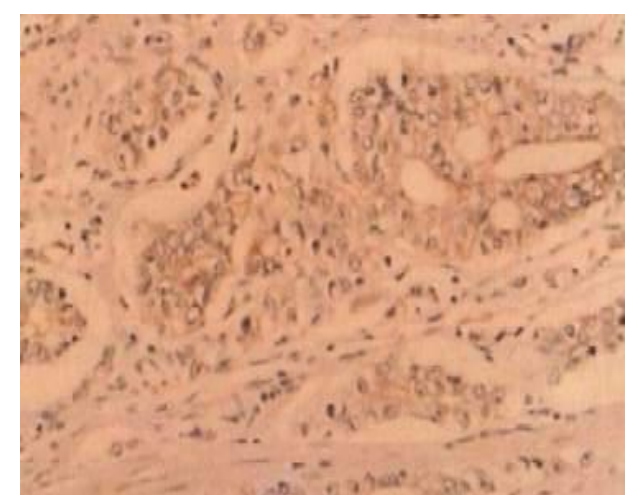

Figure 1. Trp-p8 protein-negative expression in BPH tissue.

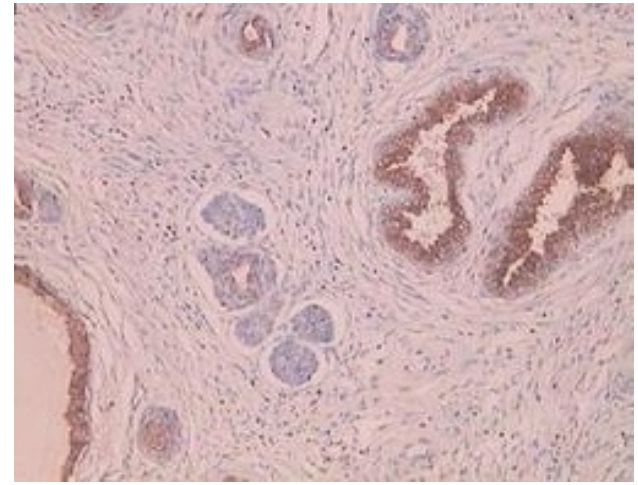

Figure 2. Trp-p8 protein strong positive expression in PCa tissue.

Table 1. Various intervals of BPH and PCa.

\begin{tabular}{cccc}
\hline PSADTZ intervals & $<0.35 \mathrm{ng} / \mathrm{ml}$ & $0.35 \mathrm{ng} / \mathrm{ml} \leq \mathrm{PSADTZ}<0.5 \mathrm{ng} / \mathrm{ml}$ & $\geq 0.5 \mathrm{ng} / \mathrm{ml}$ \\
BPH $(\mathrm{n}=30)$ & 20 & 8 & 2 \\
PCa $(\mathrm{n}=30)$ & 3 & 11 & 16 \\
\hline
\end{tabular}




\section{Correlation between Trp-p8-mRNA}

abundance and range PSADTZ

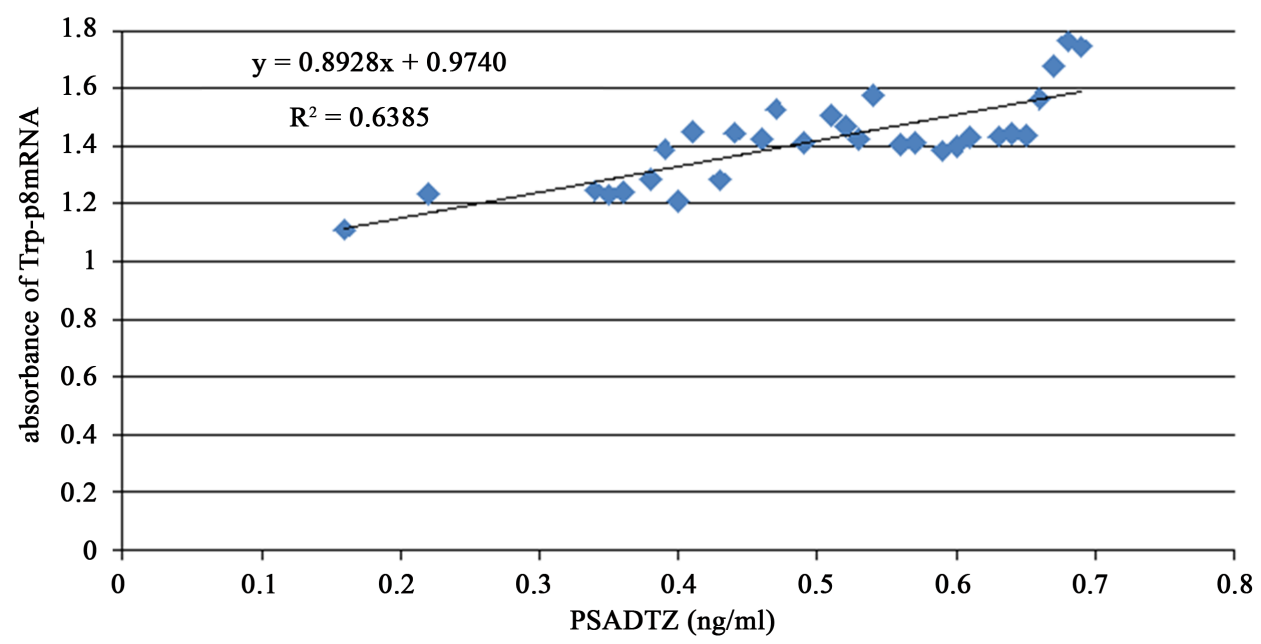

Figure 3. Correlation between Trp-p8-mRNA abundance and range PSADTZ. Note: the correlation coefficients $\mathrm{r}=0.799$. Explaining they are positively correlated.

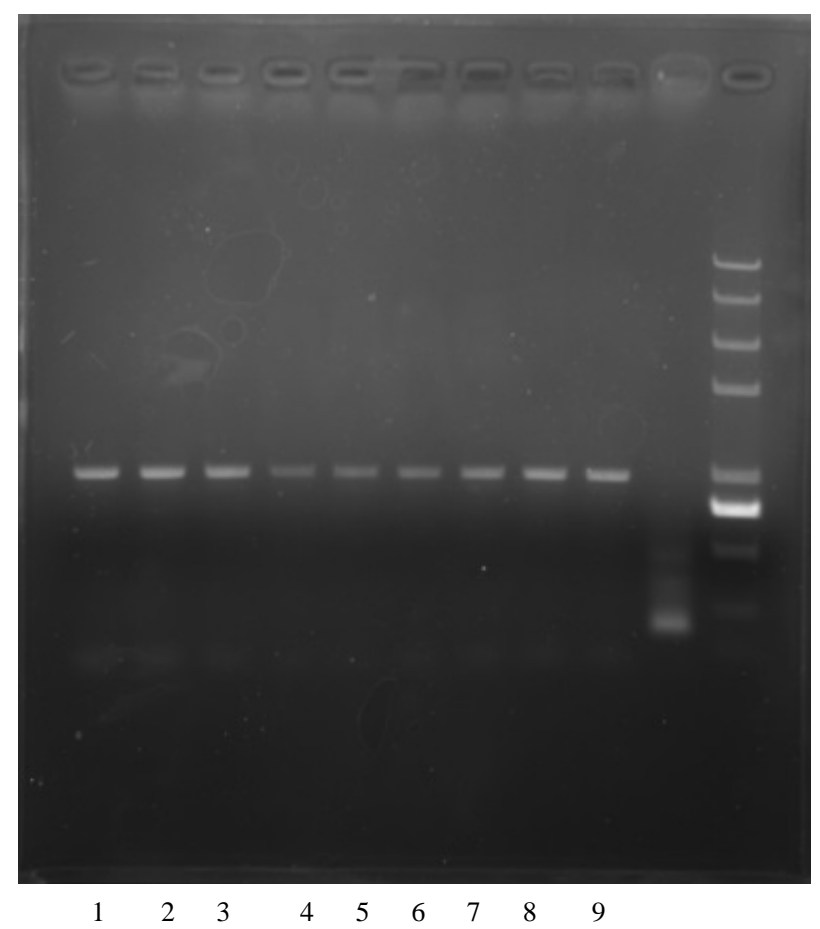

Figure 4. Trp-p8-mRNA abundance electrophoresis diagram. Note: 4, 5, 6, 7 with BPH; 1, 2, 3, 8, 9 with PCa.

Table 2. The number of expression of Trp-p8 protein cases in BPH and PCa.

\begin{tabular}{ccccc}
\hline Expression of Trp-p8 & - & \pm & + & $+5^{*}$ \\
BPH $(\mathrm{n}=30)$ & 14 & 9 & 4 & $10^{*}$ \\
PCa $(\mathrm{n}=30)$ & 1 & 45 \\
\hline
\end{tabular}

* Comparison between two groups $P<0.05$. 
Table 3. Trp-p8 protein expression of 37 patients with PSADTZ $\geq 0.35 \mathrm{ng} / \mathrm{ml}$.

\begin{tabular}{ccccc}
\hline Expression of Trp-p8 & - & \pm & + & ++ \\
\hline BPH $(\mathrm{n}=10)$ & 5 & 3 & $2^{*}$ & 0 \\
PCa $(\mathrm{n}=27)$ & 1 & 4 & $8^{*}$ & 14 \\
\hline
\end{tabular}

*Comparison between two groups $P<0.05$.

Table 4. The number of expression of Trp-p8 protein cases in various intervals of BPH and PCa.

\begin{tabular}{rcccc}
\hline PSADTZ & & $<0.35 \mathrm{ng} / \mathrm{ml}$ & $0.35 \mathrm{ng} / \mathrm{ml} \leq \mathrm{PSADTZ}<0.5 \mathrm{ng} / \mathrm{ml}$ & $\geq 0.5 \mathrm{ng} / \mathrm{ml}$ \\
\hline & - & 1 & 0 & 0 \\
expression of Trp-p8 & \pm & 2 & 2 & 0 \\
& + & 0 & 3 & 9 \\
\hline
\end{tabular}

Table 5. The expression of Trp-p8-mRNA in various intervals of BPH and PCa.

\begin{tabular}{cccc}
\hline PSADTZ intervals & $<0.35 \mathrm{ng} / \mathrm{ml}(\mathrm{n}=23)$ & $0.35 \mathrm{ng} / \mathrm{ml} \leq$ PSADTZ $<0.5 \mathrm{ng} / \mathrm{ml}(\mathrm{n}=19)$ & $\geq 0.5 \mathrm{ng} / \mathrm{ml}(\mathrm{n}=18)$ \\
\hline BPH $(\mathrm{n}=30)$ & $0.61 \pm 0.04(\mathrm{n}=20)$ & $0.63 \pm 0.02(\mathrm{n}=8)$ & $0.70 \pm 0.03(\mathrm{n}=2)$ \\
PCa $(\mathrm{n}=30)$ & $1.15 \pm 0.08^{*}(\mathrm{n}=3)$ & $1.38 \pm 0.12^{*}(\mathrm{n}=11)$ & $1.69 \pm 0.09^{*}(\mathrm{n}=16)$
\end{tabular}

*Comparison between two groups $P<0.05$.

Results show that Trp-p8 in the PSA “grey district” expressed differently in prostate disease, weaker intensity of expression of Trp-p8 in benign prostatic hyperplasia and Trp-p8 in prostate cancer expressed varying degrees of strength and expression in the high PSADTZ group has a higher strength, the difference was statistically significant $(P<0.05)$. When PSADTZ $\geq 0.35 \mathrm{ng} / \mathrm{ml}$ and Trp-p8 protein expression positive, or when PSADTZ integral value $\geq 0.35 \mathrm{ng} / \mathrm{ml}$, absorbance of Trp-p8mRNA $>1.25$, the predicted sensitivity is $72.97 \%$ and specificity of $86.96 \%$ to prostate cancer, which can be used as a diagnosis of early-stage prostate cancer prediction interval.

\section{Discussion}

Prostate cancer is the most frequent cancer in Europe and the United States in the past ten years. The incidence was significantly increased, becoming one of the most common malignant tumors in elderly men. Among them, the early prostate cancer detection rate increased, too. Imaging such as MRI's change is not significant in early prostate cancer. Now the primary target for clinical prostate cancer screening is the PSA (prostate specific antigen), but its impact is influenced by many factors. Acute prostatitis, digital rectal examination, bladder stones, catheterization may interference detection error, especially when the early screening of prostate cancer. Now prostate cancer early diagnosis relies on clinical prostate biopsy and pathological examination. But once biopsy cannot completely diagnose prostate cancer, patients may need repeat prostate biopsy after 3 months and a long time if their PSA has not decreased, which will undoubtedly increase the patient's mental and physical pain and financial burden. Current serum PSA greater than $4 \mathrm{ng} / \mathrm{ml}$ as a prostate biopsy is often indicated. But Gretzer [4] found that when serum PSA concentrations in $4-10 \mathrm{ng} / \mathrm{ml}$, its sensitivity and specificity for diagnosis of PCa and BPH differences were not statistically significant. In this way, many of the not prostate cancer patients received unnecessary repeated prostate biopsy. For patients with more than $4 \mathrm{ng} / \mathrm{ml}$ of PSA repeated, it has been troubled by problems of urologists on the basis of how to reduce the number of prostate biopsy while prostate cancer detection rate improved.

Serum PSA concentrations generally believed was positively correlated with prostate volume. PSAD is prostate volume correction for density (PSAD). PSAD is considered the possibilities of elevated serum PSA in large prostatic size. Kalish [5] further analyzed PSADTZ (PSA density of transition zone) concept, namely the ratio of serum PSA and prostate transition zone volume used in identification of PCa. Benign prostatic hyperplasia oc- 
curs mainly in the transitional zone, while PCa mainly occur in peripheral zones. PSADTZ is considered as the increase parts of prostate tissue, which may improve the diagnostic sensitivity and specificity of the PCa. Tanaka [6] has researched to the 235 patients with PSA values in $4-10 \mathrm{ng} / \mathrm{ml}$ (of which 55 patients with pathologically confirmed PCa). The analysis showed that PSADTZ has higher diagnostic value for PCa. Ji Guoyi’s [7] research showed that differences of prostate transitional district volume, PSA, and PSAD and PSADTZ had statistics meaning in BPH and PCa two groups. Those indicators in all patients compared differences have statistics meaning.

In order to improve the specificity and sensitivity of detection of PCa, multiple tumor marker detection method has been proposed. In the earlier work we [8] [9] had confirmed by RT-PCR and immunohistochemistry methods that Trp-p8 is expression of different in patients with BPH and prostate cancer. Determination of Trp-p8 with PSADTZ as a scale to predict prostate cancer tumors, the idea have not been reported both at home and abroad. This study shows that Trp-p8 in the PSA "grey area" expressed differently in prostate disease. Meanwhile, we can detect the expression of Trp-p8 protein intensity difference in prostate tissue from patients. The blood sample can be detected to Trp-p8-mRNA differences in the abundance, which is positively correlated with the PSADTZ value. It offers new ideas for our clinical screening for early-stage prostate cancer: It may be possible that we can establish a criterion interval to predict which patients diagnosed with prostate cancer through the combination of Trp-p8 and PSADTZ value of strength.

Prostate biopsy of prostate cancer was diagnosed as a "gold standard". Due to a prostate biopsy in clinical work cannot be fully diagnosed patients diagnosed with prostate cancer, high-risk patients often require multiple prostate biopsy to confirm the diagnosis. As traumatic examination, prostate biopsy has impact on a patient's physical pain, mental stress, economic pressure, and so on. How to improve prostate cancer detection rate on the basis of reduce the number of prostate biopsy has become an important subject.

\section{Conclusions}

The expression of Trp-p8 in prostate tissues of PSA in grey district was different and the expression in prostate cancer was higher than that in benign prostatic hyperplasia group, and this expression was positively correlated with the PSADTZ values. This study showed that PSADTZ was more than or equal to $0.35 \mathrm{ng} / \mathrm{ml}$ and Trp-p8 mRNA integral absorbance in the blood of patients was greater than 1.25 . The prostate cancer predicted sensitivity was $72.97 \%$ and the specificity was $86.96 \%$. This interval is important to diagnose early-stage prostate cancer as a prediction interval. For patients located in this range, you need to consider prostate biopsy. Prediction intervals in which some patients can be closely monitoring PSA levels and suspension piercing avoid adding unnecessary emotional, financial and physical burden of patients with pain. So patients can avoid prostate biopsy pain and risk, reduce screen time. And the rate of early diagnosis can be improved.

In view of the limitations on the PSA for prostate cancer, this study introduces the ideas of PSADTZ and Trp-p8 combined for the first time. It provides a theoretical basis and clinic choice for urologists on the basis of how to reduce the number of prostate biopsy while prostate cancer detection rate improves. Of course, we also needs to clarify the possibilities of missed diagnosis of prostate cancer for patients defer puncture and get their full understanding, so as to avoid unnecessary disputes. Due to the small sample size of this study, the correlation between Trp-p8, PSADTZ and prostate cancer is lack of large-sample test data, so appropriate diagnostic process and the establishment of reference data all need further discussion, which we need to study the issue in depth.

\section{Approved}

Our study is approved by ethics committee of Taizhou central hospital.

\section{Conflict}

On behalf of all authors, the corresponding author states that there is no conflict of interest.

\section{References}

[1] Barritt, G. and Rychkov, G. (2005) TRPs as Mechanosensitive Channels. Nature Cell Biology, 7, 105-107. http://dx.doi.org/10.1038/ncb0205-105 
[2] Moon, D.G., Cheon, J., Kim, J.J., Yoon, D.K. and Koh, S.K. (1999) Prostate-Specific Antigen Adjusted for the Transition Zone Volume versus Free-to-Total Prostate-Specific Antigen Ratio in Predicting Prostate Cancer. International Journal of Urology, 6, 455-462. http://dx.doi.org/10.1046/j.1442-2042.1999.00089.X

[3] Yang, X.R., Lin, M.J., McIntosh, L.S. and Sham, J.S.K. (2006) Functional Expression of Transient Receptor Potential Melastatin- and Vanilloid-Related Channels in Pulmonary Arterial and Aortic Smooth Muscle. American Journal of Physiology_Lung Cellular and Molecular Physiology, 290, L1267-L1276. http://dx.doi.org/10.1152/ajplung.00515.2005

[4] Gretzer, M.B. and Partin, A.W. (2003) PSA Markers in Prostate Cancer Detection. Urologic Clinics of North America, 30, 677-686. http://dx.doi.org/10.1016/S0094-0143(03)00057-0

[5] Kalish, J., Coone, W.H. and Graham Jr., S.D. (1994) Serum PSA Adjusted for Volume of Transition Zone (PSAT) Is More Accurate than PSA Adjusted for Total Gland Volume (PSAD) in Detecting Adenocarcinoma of the Prostate. Urology, 43, 601-606. http://dx.doi.org/10.1016/0090-4295(94)90170-8

[6] Tanaka, N., Fujimoto, K., Chihara, Y., et al. (2007) Prostatic Volume and Volume-Adjusted Prostate-Specific Antigen as Predictive Parameters for Prostate Cancer Patients with Intermediate PSA Levels. Prostate Cancer and Prostatic Diseases, 10, 274-278. http://dx.doi.org/10.1038/sj.pcan.4500957

[7] Ji, G.Y., Pan, Y.Z., Wang, W.H., et al. (2007) The Role of PSA Density in Transitional Zone in the Early Diagnosis of Prostate Cancer PSA in Grey District. China Laboratory Diagnostics, 11, 1353-1355.

[8] Zhang, X.S., Zhang, Y. and Chen, Q. (2012) Determination of Trp-p8 in the Diagnosis of Prostate Cancer. Zhejiang Medical Journal, 34, 66-67.

[9] Zhang, X.S., Zhang, Y., Xu, J.X., et al. (2012) Expression of Trp-p8 in Prostate Cancer Tissues of PSA in Grey District. Chinese Journal of Surgery of Integrated Traditional and Western Medicine, 18, 241-244. 